\title{
Reconstruint la història de les poblacions humanes
}

\author{
David Comas \\ Unitat de Biologia Evolutiva, Departament de Ciències Experimentals i de la Salut, Univ. Pompeu Fabra \\ david.comas@upf.edu
}

Les tècniques de recerca de la genètica ens permeten seguir la pista del poblament humà de la Terra. Podem saber on va començar la humanitat i quant de temps fa, així com força detalls del procés d'expansió i migració de la població.

Paraules clau: genoma humà, races, ADN, cromosomes, llinatge

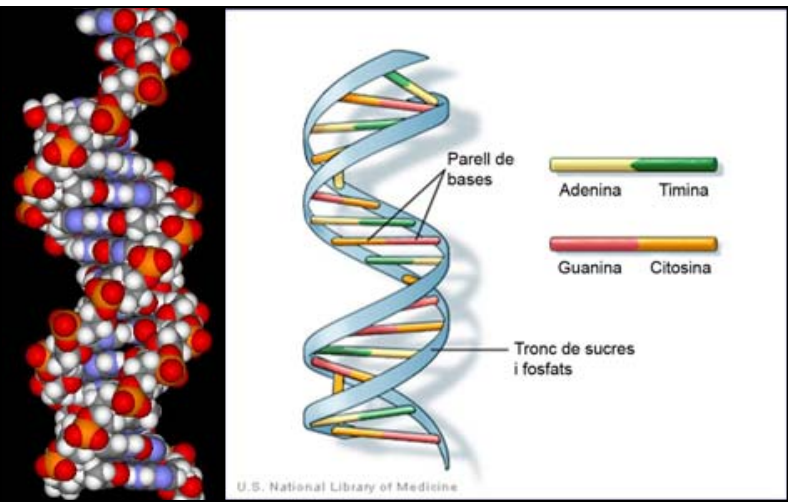

Pretendre conèixer amb cert detall de quina manera es produí l'expansió de l'espècie humana per tota la Terra pot semblar a primer cop d'ull un repte impossible. Es tracta de fets que es remunten a milers d'anys enrere i que han deixat pocs rastres... excepte nosaltres mateixos.

Però actualment la biologia disposa d'eines que permeten accedir a la nostra pròpia informació genètica, fent possible reconstruir parts substancials del passat de la nostra espècie.

En el marc del projecte Genographic, fruit de la col-laboració entre National Geographic i IBM, investiguem els detalls de l'expansió humana per la Terra. Vegem com es fa.

\section{El genoma humà}

Com és sabut, la informació genètica o genoma, rau en el nucli de la cèl.lula en forma de nucleòtids (A, C, G, i T) de la cadena d'ADN.
A l'espècie humana el genoma està format per una seqüència de 3000 milions de nucleòtids, repartits en 23 parells de cromosomes.

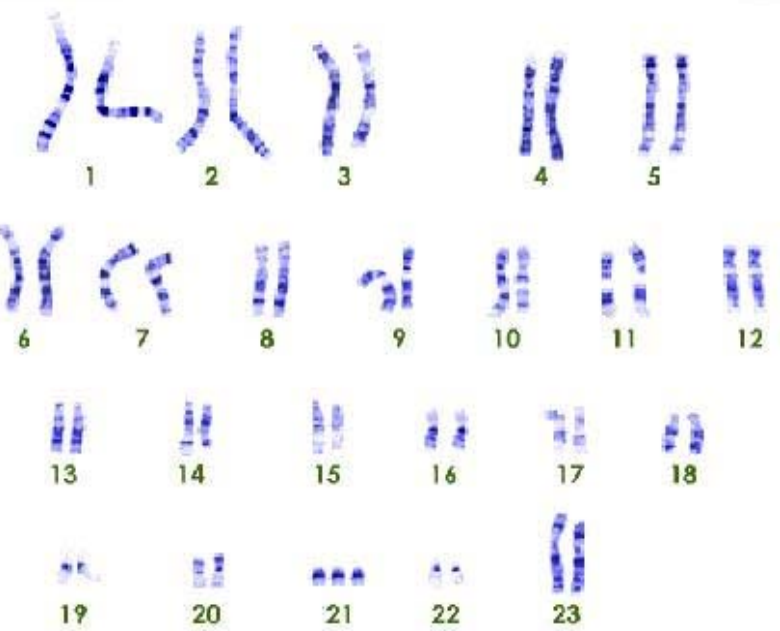

Es tracta d'un nombre molt proper al dels ximpanzés, que disposen de 24 parells, mentre que hi ha plantes que arriben als 70 i 80 parells de cromosomes.

Dels nostres 3000 milions de nucleòtids una part realitzen alguna funció biològica i constitueixen el que anomenem gens. Abans de desxifrar el genoma humà es pensava que estaria format per uns 100.000 gens, però la recerca ens ha mostrat que eren molts menys: només 20.000 o 30.000 gens. Això significa que només un 1'5\% del genoma codifica informació, un resultat força inesperat. 
Per altra banda, les diferències genètiques entre individus podríem pensar que han de ser importants atenent a l'aparent diversitat ètnica (fig 1).

Però el cas és que aquestes diferències entre individus suposen únicament un 0'1\% del genoma, és dir, poden arribar a 3 milions de nucleòtids. I això és un nombre gran o petit? Per fer-nos-en una idea podríem comparar-ho amb els ximpanzés i veuríem que aquesta diversitat humana és entre $5 \mathrm{i}$ 10 vegades menor que la que hi ha entre aquests animals.

Un resultat sorprenent. A què es pot atribuir?
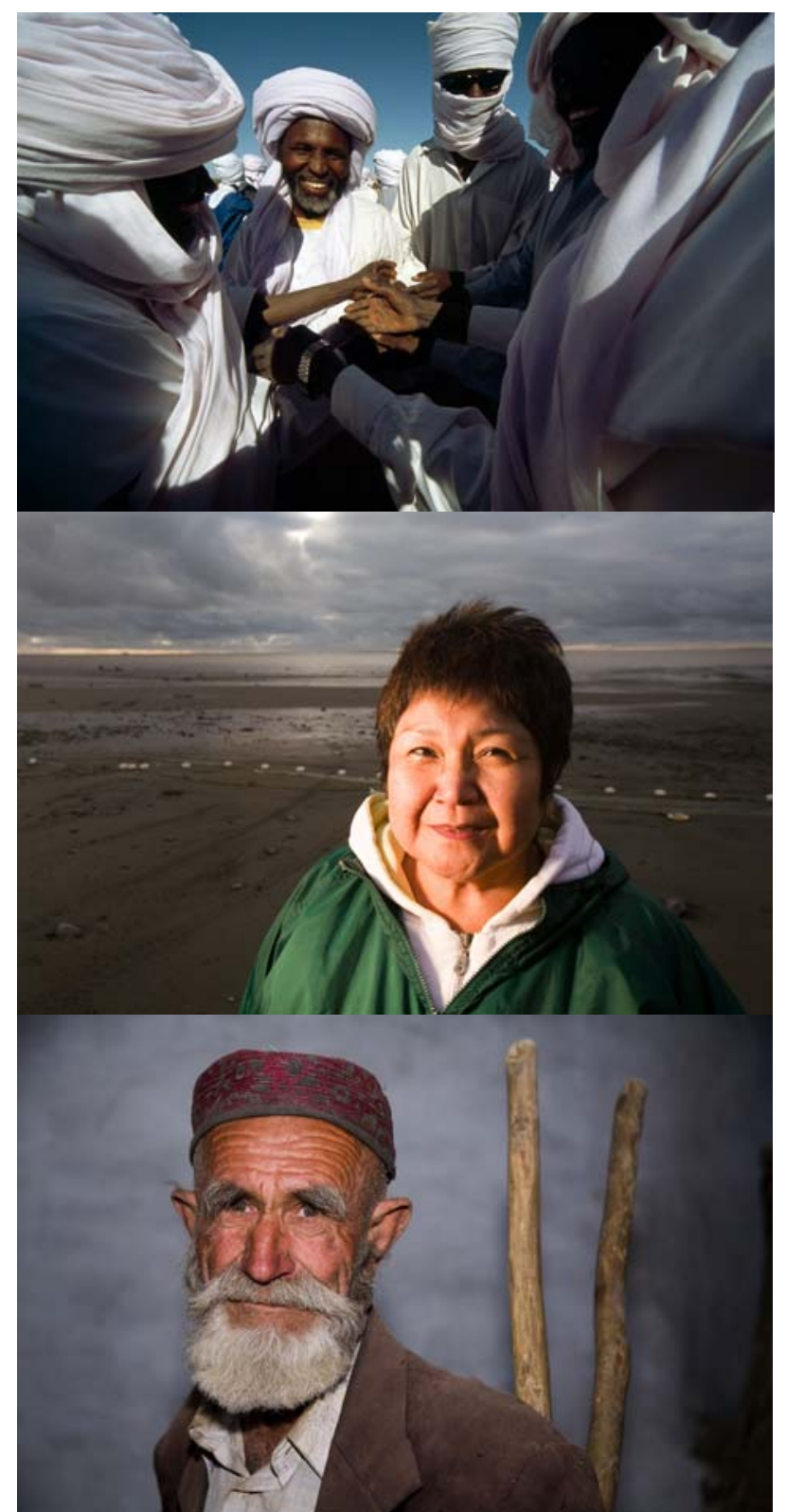

Figura 1. Persones del Txad, d'Alaska i del Tadjikistan. (Font: Genographic)
Doncs a l'origen relativament recent de la nostra espècie per comparació amb la dels ximpanzés: els humans hem tingut força menys temps que ells per acumular canvis en el genoma. Efectivament, les dues espècies ens vam separar fa 6 milions d'anys, mentre que nosaltres descendim d'individus que van viure fa només 200.000 anys a l'Àfrica.

Aleshores, per què notem diferències tan grans entre els humans? Únicament per raons subjectives, perquè, de fet, les diferències estan codificades per un nombre relativament reduït de variants genètiques.

Una altra dada genètica que relativitza les nostres diferències és que el $90 \%$ d'elles de fet es troben dins de les poblacions, mentre que només un $10 \%$ donen compte de les diferències -que ens poden semblar importants-, entre diverses poblacions, que és el que ens crida més l'atenció de les fotografies de la fig. 1.

\section{A què són degudes aquestes diferències?}

Hi ha dos tipus de mecanismes que poden explicar aquesta variabilitat genètica.

El primer grup té relació amb l'adaptació al medi: la quantitat de llum solar, l'adaptació a patògens (hi ha variants genètiques que provoquen resistència a microorganismes patògens), processos culturals (per exemple, el costum de beure llet pot haver seleccionat a la població els enzims necessaris per digerir la lactosa), etc. En l'altre grup de processos hi hauria els de tipus històric en la població (efecte de les migracions, de l'aïllament, de la barreja de poblacions, de factors demogràfics...)

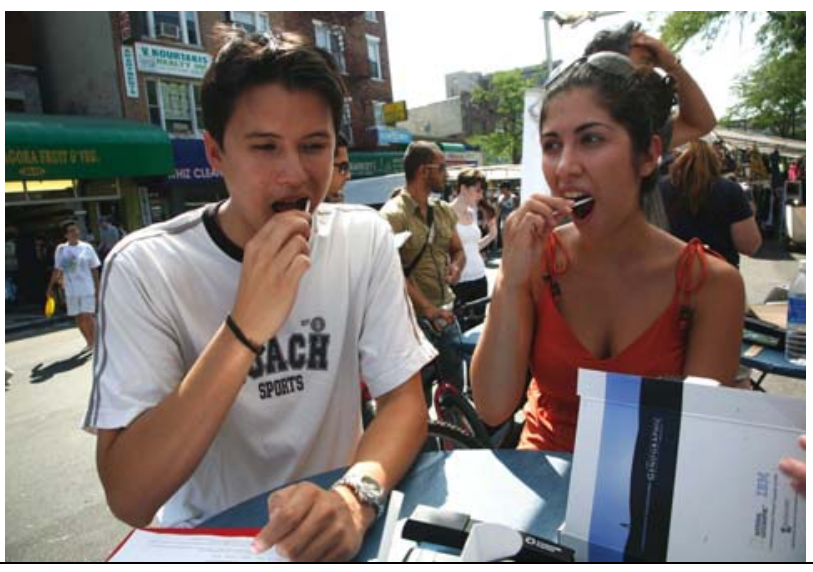

Figura 2. Dues persones obtenint mostres de la seva boca per al projecte Genographic. (Font: Genographic) 


\section{El projecte Genographic}

Per reconstruir la història de les poblacions humanes cal obtenir mostres de cèl-lules de persones ben diverses. S'aconsegueixen mitjançant un senzill raspat bucal (fig. 2).

Però l'anàlisi genètica és més fàcil de fer a partir de la sang i és per aquest motiu que també se n'obtenen mostres (fig. 3), sempre seguint tots els requeriments ètics que s'han establert: tenir majoria d'edat, donar lliurement el seu consentiment després haver estat prou informats, etc.

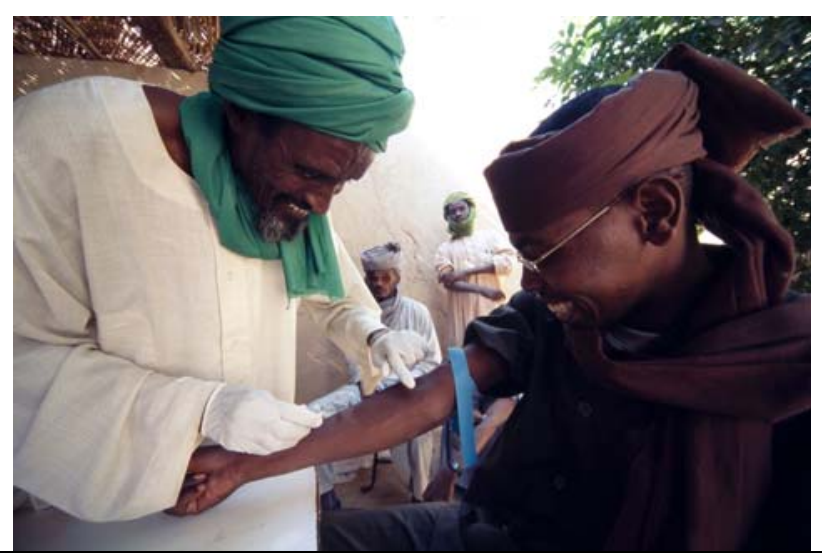

Figura 3. Extracció de sang per a l'obtenció de mostres genètiques. (Font: Genographic)
La tècnica d'anàlisi que s'utilitza ja acumula una experiència d'uns vint anys. Es tracta de marcadors genètics que permeten establir les variants pròpies de les regions estudiades. Hi ha marcadors al cromosoma $Y$ que permeten seguir el llinatge patern, mentre que d'altres a l'ADN mitocondrial permeten evidenciar el llinatge matern.

Un cop recollides les dades és possible determinar l'antiguitat d'un genoma concret a partir del nombre de mutacions que ha acumulat: com més temps ha passat, més mutacions ha tingut.

Sobre aquesta base s'ha arribat a establir que els genomes més antics, corresponents als que podríem anomenar "Adam Y" i "Eva africana", tenen una antiguitat de 200.000 anys. S'havia pensat que l'antiguitat del genoma devia ser de prop d'un milió d'anys, però ara constatem que és força més recent i d'origen africà.

\section{Alguns resultats}

Entre els resultats que hem anat obtenint n'hi ha de més o menys curiosos o inesperats.

Per exemple, hem trobat que a la illa de Cuba gairebé no queden restes genètiques dels seus pobladors originals, els ciboneys i els taínos, substituïts pel genoma d'europeus i esclaus africans.

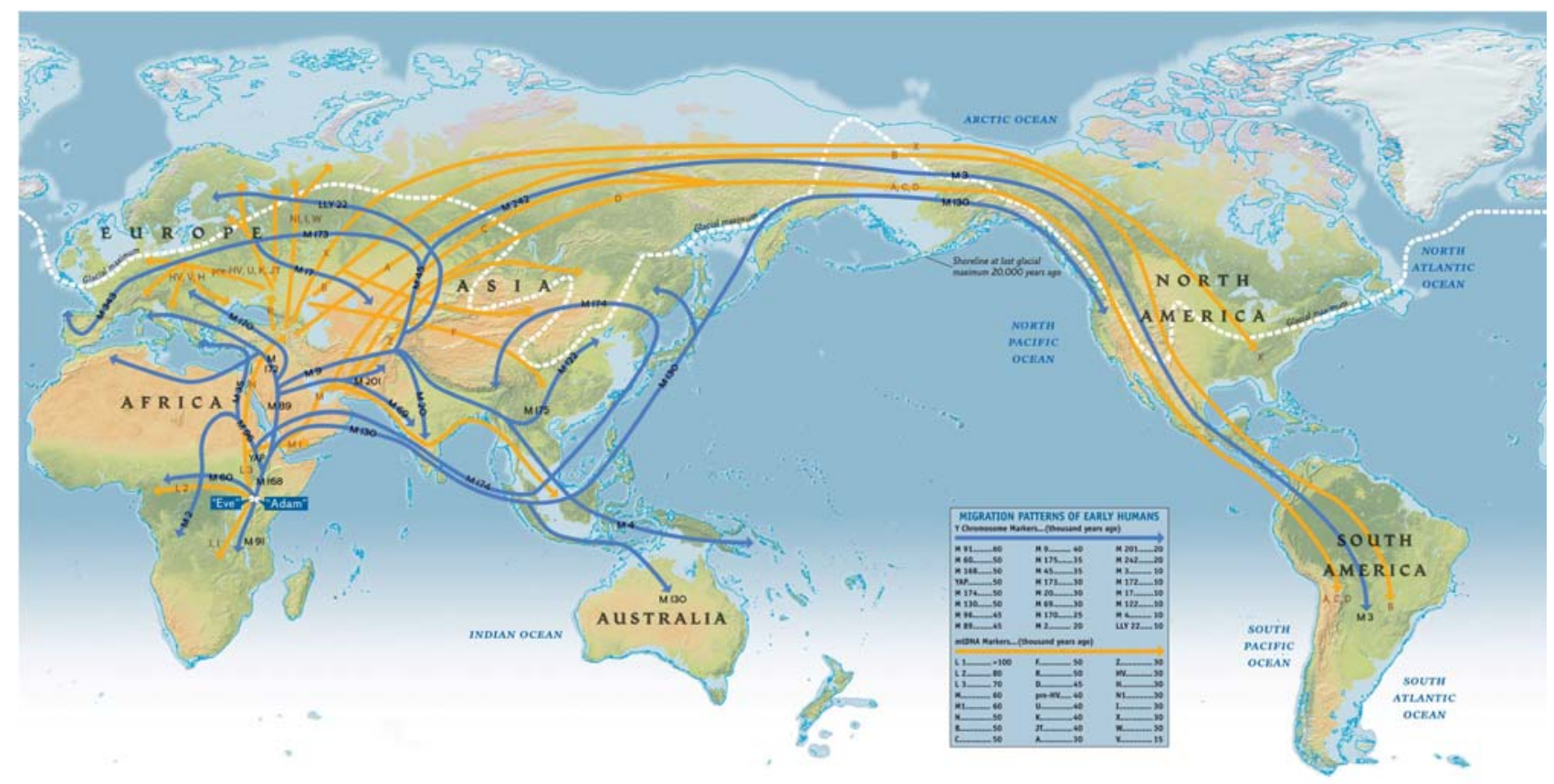

Figura 4. Les anàlisis genètiques mostren les grans rutes d'expansió i migració de la humanitat. (Font: Genographic) 
De l'anàlisi genètica corresponent del cromosoma $Y$ es dedueix que a Cuba el $80 \%$ dels llinatges masculins actuals són d'origen europeu, mentre que el $20 \%$ restant és de procedència africana; en canvi, l'ADN mitocondrial mostra que els llinatges femenins procedeixen només en un $20 \%$ dels europeus, per darrera dels africans, amb un $50 \%$, i dels amerindis, amb el 30\% restant. Això dóna pistes força clares de quines eren les pautes reproductives durant la colonització.

Un altre dels resultats d'aquests estudis és la manca de fonament del concepte de raça.

Efectivament, les diferències genètiques observades en les poblacions mostren una distribució contínua en l'espai. Així, mentre que grups molt separats mostren un nombre important de diferències entre elles, als territoris entre ells s'hi observa una variació continuada, fent impossible d'establir uns límits definits entre ells.

Hem arribat també a conèixer les grans rutes de propagació de la humanitat (fig. 4).

Sabem que el nostre origen és subsaharià, amb uns 200.000 anys d'antiguitat. Que la humanitat va restar a l'Àfrica, sense sortir-ne, durant uns
150.000 anys, fent que la diversitat genètica de la població africana sigui, amb diferència, la més alta del món. I que fa uns 50.000 o 60.000 anys un petit grup, potser per raons climàtiques (segurament un refredament del clima), van migrar cap al sud de l'Àsia, arribant fins a Austràlia 50.000 anys enrere.

Curiosament, s'arribà a Europa força després (fa 40.000 anys) que a Austràlia, tot i la proximitat. Un dels possibles motius és que a Europa hi havia neandertals que devien dificultar-los la penetració.

Entre $-30.000 \mathrm{i}-15.000$ anys no va ser possible l'arribada a Amèrica perquè el pas des de l'Àsia era infranquejable a causa del glaç. Per això no va ser fins fa només 15.000 anys que finalment es va arribar a Amèrica. Aquest és el motiu que explica que la diversitat genètica de la població autòctona sigui força limitada.

\section{Referències}

Projecte Genographic: https://genographic.nationalgeographic.com/gen ographic/index.html 